\title{
CaMKII $\beta$ in Neuronal Development and Plasticity: An Emerging Candidate in Brain Diseases
}

\author{
Olivier Nicole $^{1}\left(\mathbb{D}\right.$ and Emilie Pacary ${ }^{2, *(1)}$ \\ 1 CNRS, UMR5293 Institut des Maladies Neurodégénératives, University of Bordeaux, \\ F-33000 Bordeaux, France; olivier.nicole@u-bordeaux.fr \\ 2 INSERM, Neurocentre Magendie, U1215, University of Bordeaux, F-33000 Bordeaux, France \\ * Correspondence: emilie.pacary@inserm.fr
}

Received: 15 September 2020; Accepted: 29 September 2020; Published: 1 October 2020

check for updates

\begin{abstract}
The calcium/calmodulin-dependent protein kinase II (CaMKII) is a ubiquitous and central player in $\mathrm{Ca}^{2+}$ signaling that is best known for its functions in the brain. In particular, the $\alpha$ isoform of CaMKII has been the subject of intense research and it has been established as a central regulator of neuronal plasticity. In contrast, little attention has been paid to CaMKII $\beta$, the other predominant brain isoform that interacts directly with the actin cytoskeleton, and the functions of CaMKII $\beta$ in this organ remain largely unexplored. However, recently, the perturbation of CaMKII $\beta$ expression has been associated with multiple neuropsychiatric and neurodevelopmental diseases, highlighting $C A M K 2 B$ as a gene of interest. Herein, after highlighting the main structural and expression differences between the $\alpha$ and $\beta$ isoforms, we will review the specific functions of CaMKII $\beta$, as described so far, in neuronal development and plasticity, as well as its potential implication in brain diseases.
\end{abstract}

Keywords: CaMKII; brain; neuronal development; neuronal plasticity; neurodevelopmental disorders; psychiatric diseases

\section{Features of CaMKII $\beta$}

\subsection{CaMKII $\beta$ Structure and Properties}

The calcium/calmodulin-dependent protein kinase II (CaMKII), which is a serine/threonine protein kinase, is one of the most abundant proteins in the brain [1]. There are four isoforms of CaMKII $(\alpha, \beta, \gamma, \delta)$ that are encoded by four distinct but highly related genes (CAMK2A, CAMK2B, $C A M K 2 G, C A M K 2 D)$ located on different chromosomes. Although these isoforms show strong sequence similarities [2], they present different biochemical properties and localization [3,4]. As an example, CaMKII $\alpha$ is absent from amphibians (Xenopus laevis) and it has the most restricted tissue specificity in mammals [2,3].

CaMKII is a unique neuronal signaling protein that is composed of $12-14$ subunits (for reviews $[5,6]$ ). In the brain, CaMKII predominantly consists of the $\alpha$ and $\beta$ isoforms, which form heteromeric or homomeric complexes. CaMKII $\alpha$ and $\beta$, like the two other isoforms, consist of four distinct domains: a catalytic domain containing the active site that is required for CaMKII kinase activity, a regulatory domain that comprises a self-inhibitory region and a binding site for the $\mathrm{Ca}^{2+} / \mathrm{CaM}$ complex, a variable domain and a hub or association domain necessary for assembly of the 12-14 subunits (Figure 1A). The kinase activity is regulated by the autoinhibitory regulatory segment, which blocks the substrate binding site in the absence of $\mathrm{Ca}^{2+}$. In response to an increase in intracellular $\mathrm{Ca}^{2+}$ concentration, $\mathrm{Ca}^{2+}$-bound calmodulin $\left(\mathrm{Ca}^{2+} / \mathrm{CaM}\right)$ competitively binds to the regulatory segment and it relieves inhibition by exposing the substrate-binding site (Figure 1B). This binding causes autophosphorylation at Thr286 (on CaMKII $\alpha$ ) or Thr287 (on CaMKII $\beta$ ) and it makes CaMKII activity $\mathrm{Ca}^{2+}$-independent [6]. 
A

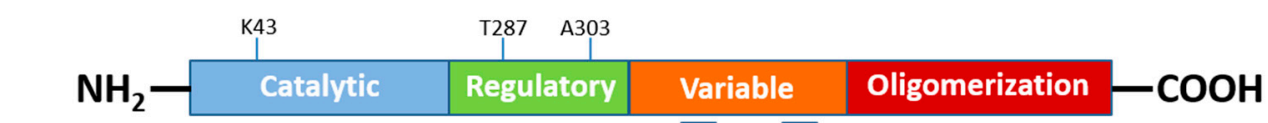

K43: ATP binding

T287: Autophosphorylation site

A303: $\mathrm{Ca}^{2+/} \mathrm{CaM}$ binding site

V1: F-actin binding domain

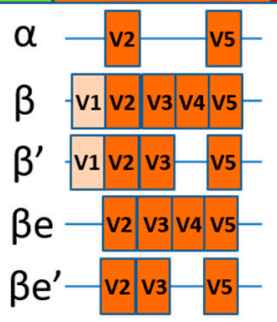

$\alpha$

$\beta \quad-v_{1} v_{2} v_{3} v_{4} v_{5}-$

$\beta^{\prime} v_{1} v_{2} v_{3}-v_{5}-$

$\beta e-v_{2} v_{3} v_{4} v_{5}-$

$\beta e^{\prime}-v_{2} v_{3}-v_{5}-$
B

Kinase « off »

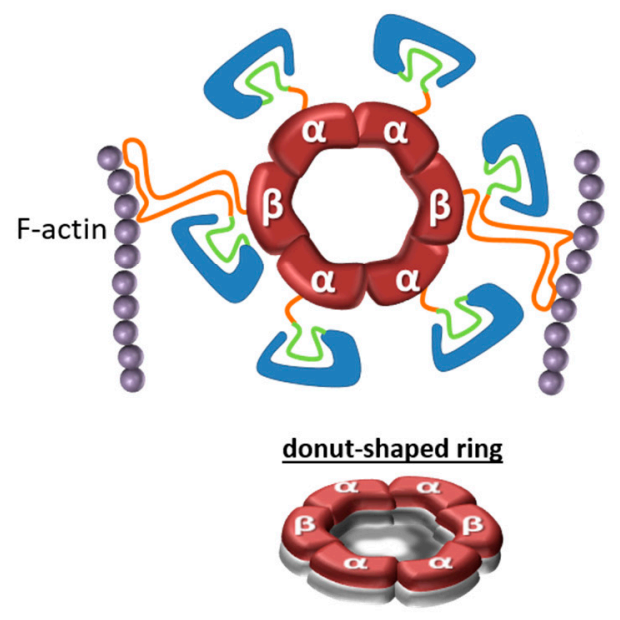

Kinase " on "

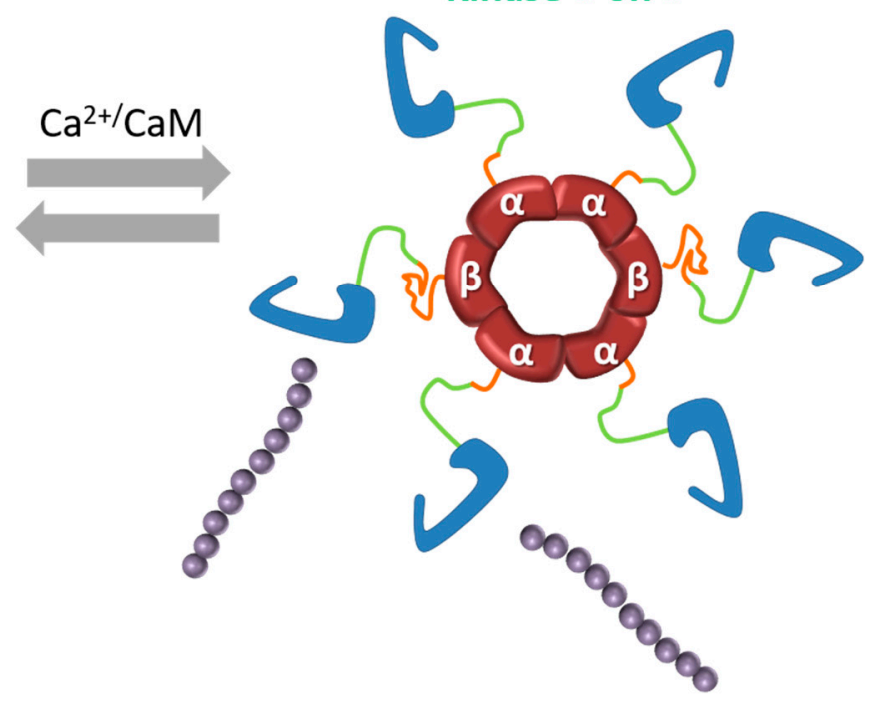

Figure 1. Structural organization of CaMKII $\beta$. (A). Schematic representation of CaMKII $\beta$ structure and its variants. CaMKIII $\alpha$ and CaMKII $\beta$ differ mostly in the variable region. The variable region of CaMKIII $\alpha$ only contains V2 and V5 domains. The variable region V1, which is absent in CaMKIIße and CaMKII $\beta$ 'e, is necessary for the binding to the actin cytoskeleton. (B) Calcium/calmodulin-dependent protein kinase II (CaMKII) is organized into large oligomers typically of 12 or 14 subunits. Central to the organization of CaMKII is the hub domain, also known as the association or oligomerization domain, which forms a donut-shaped ring that is the core of the holoenzyme (see side view). The kinase domains are tethered to the central hub by the regulatory segments. In basal condition, the CaMKII holoenzymes, via CaMKII $\beta$, bind to actin filaments, particularly in dendritic spines. Upon $\mathrm{Ca}^{2+}$ influx, $\mathrm{Ca}^{2+} / \mathrm{CaM}$ binds to a CaM-binding element in the regulatory segment of CaMKII, releasing it from the kinase domain and thereby activating the enzyme. At the same time, CaMKII holoenzymes detach from F-actin and it can be recruited to the synapse to induce functional changes.

Although the two main brain isoforms show similar domain structure and high sequence homology (89\%-93\% sequence homology in the catalytic and regulatory domains in rats) [7], they differ within the N-terminal part of the variable region, where CaMKII $\beta$, but not CaMKII $\alpha$, contains a filamentous actin (F-actin) binding domain (FABD) (Figure 1A). CaMKII $\beta$ not only binds to actin [8], but it is also capable of bundling actin thanks to its actin-binding and association domains [9]. This bundling feature is achieved by the CaMKII oligomers binding to multiple actin filaments. It should be mentioned that the variable region, where $\mathrm{CaMKII} \alpha$ and $\beta$ differ most, is subject to alternative splicing in all CaMKII isoforms. Regarding CaMKII $\beta$, four splicing variants, $\beta, \beta^{\prime}, \beta e$, and $\beta^{\prime}$ e, were discovered in the brain, but only $\beta$ and $\beta^{\prime}$ variants contain a FABD and are, therefore, able to bind to F-actin [10-13] (Figure 1A).

Besides actin, CaMKII $\beta$ has been shown to specifically interact with some targets, but not CaMKII $\alpha$, such as Arc/Arg3.1 [14] or the centrosomal targeting protein PCM1 (pericentriolar material 1) [15]. 
In addition to these differences in susbstrate specificity, the two isoforms have different sensitivities to $\mathrm{Ca}^{2+}$ signals, since the binding affinity for calmodulin is higher for CaMKII $\beta$ homomers than for CaMKII $\alpha$ homomers [4]. Moreover, the rate of autophosphorylation is also more elevated for $\beta$ than $\alpha[16]$.

\subsection{CaMKII $\beta$ Expression in the Nervous System}

Another important difference between the two major brain CaMKII isoforms is their temporal expression (Table 1). Indeed, CaMKII $\beta$ is already expressed in the brain during embryonic life, starting around E12.5, whereas CaMKII $\alpha$ starts to be expressed after birth and it becomes predominant in juvenile animals $[3,17,18]$. Regional differences also exist in the expression of the CaMKII $\alpha$ and CaMKII $\beta$ isoforms. For example, although they are both expressed in the forebrain and cerebellum, CaMKII $\alpha$ is predominant in the adult hippocampus and neocortex $[1,4,19]$, whereas CaMKII $\beta$ is the dominant isoform in the cerebellum $[1,3,19,20]$. At the cellular level, CaMKII $\alpha$ and CaMKII $\beta$ are mainly expressed in excitatory pyramidal neurons in the cortex and hippocampus, but only CaMKII $\beta$ is found in inhibitory interneurons in these regions [21-23]. In the cerebellum, CaMKII $\alpha$ is only expressed in Purkinje cells, whereas CaMKII $\beta$ is also present in granule cells [24]. At the neuron subcellular level, CaMKII $\beta$ is localized in dendrites and particularly enriched in filopodia and mature spines [8]. In addition to neurons, CaMKII $\beta$ is found in oligodendrocytes $[25,26]$.

Table 1. Schematic representation of temporal and regional expression of CaMKII $\alpha$ and CaMKII $\beta$.

\begin{tabular}{cccc}
\hline & & CaMKII $\alpha$ & CaMKII $\beta$ \\
\hline \multirow{2}{*}{ Temporal expression (total brain) } & Embryonic life & $-{ }^{2}$ & $+{ }^{3}$ \\
& Post-natal & + & ++ \\
& Adult & +++ & ++ \\
\hline \multirow{2}{*}{ Regional expression (adult brain) } & Hippocampus & +++ & + \\
& Cerebral cortex & +++ & + \\
& Cerebellum & + & +++ \\
\hline Cellular expression & Excitatory pyramidal neurons ${ }^{1}$ & + & + \\
& Inhibitory interneurons ${ }^{1}$ & - & + \\
& Purkinje cells & + & + \\
& Cerebellar granule neurons & - & + \\
\hline
\end{tabular}

${ }^{1}$ In cerebral cortex and hippocampus; ${ }^{2}-$ indicates not expressed; ${ }^{3}+$ indicates expressed.

In the mature brain, the full-length variant CaMKII $\beta$ predominate in most brain regions, except in the hypothalamus and brainstem where equal $\beta$ and $\beta^{\prime}$ are detected [11]. In the whole embryonic brain, $\beta$ e predominate at E16 and E18 [11]. However, in the embryonic cerebral cortex, $\beta$ and $\beta^{\prime}$ proteins are dominant at E16.5 [18].

Although CaMKII $\alpha$ and $\beta$ have been simultaneously discovered at the beginning of the 80's [27], CaMKII $\beta$ has received far less attention. CaMKII $\beta$ has often been relegated to a redundant role within heteromeric complexes or as a scaffold that is responsible for targeting CaMKII enzyme to F-actin [8]. Nevertheless, in the last years, several mutant constructs (Table 2) and mice (Table 3) have been developed and have allowed uncovering specific functions for CaMKII $\beta$ in the brain. In the next two sections, we will review its roles in neuronal development and plasticity. 
Table 2. CaMKII $\beta$ mutants.

\begin{tabular}{|c|c|c|}
\hline Name & Description & References \\
\hline CaMKII $\beta-T 287 D$ & Constitutively active mutant & {$[12,17,28,29]$} \\
\hline CaMKII $\beta-A 303 R$ & $\mathrm{Ca}^{+} / \mathrm{CaM}$ binding-deficient mutant & {$[12,17,28,29]$} \\
\hline CaMKII $\beta-K 43 R$ & Impaired for ATP binding, kinase inactive mutant & {$[9,12,28,29]$} \\
\hline $\begin{array}{l}\text { CaMKII } \beta 285-542 \\
\text { CaMKII } \beta 344-542\end{array}$ & $\begin{array}{l}\text { Mutants lacking kinase domain but containing } \\
\text { F-actin binding and association domains }\end{array}$ & [9] \\
\hline CaMKII $\beta-\triangle F A B D$ & Mutant without F-actin binding domain & {$[15,18]$} \\
\hline СаMKII $\beta 1-401$ & Mutant without association domain & [9] \\
\hline CaMKII $\beta-\Delta$ asso & Mutant without association domain & {$[15,18]$} \\
\hline СаMKII $\beta 285-401$ & Mutant without kinase and association domains & [9] \\
\hline CaMKII $\beta-\triangle \mathrm{CTS}$ & Mutant without centrosomal targeting sequence & {$[15,18]$} \\
\hline CaMKII $\beta$-All A & $\begin{array}{c}\text { Phosphoblock All A mutant (all S and T residues } \\
\text { within the FABD are changed to alanine) }\end{array}$ & {$[18,30]$} \\
\hline CaMKII $\beta$-All D & $\begin{array}{c}\text { Phosphomimetic All D mutant (all S and T residues } \\
\text { within the FABD are changed to aspartic acid), } \\
\text { loss of F-actin-binding activity }\end{array}$ & {$[18,30]$} \\
\hline
\end{tabular}

Table 3. Camk $2 b$ mutant mice.

\begin{tabular}{|c|c|c|}
\hline Name & Description & References \\
\hline Camk2b-/- & Deletion exon 11 & [20] \\
\hline Camk2b-/- & Deletion exon 2 & {$[31]$} \\
\hline Camk $2 b^{-/-}$ & $\begin{array}{l}\text { Camk2bff (loxP sites flanking exons 7-8) } \\
\text { crossed with a CMV-Cre mouse }\end{array}$ & [32] \\
\hline Camk2bff & LoxP sites flanking exon 2 & [33] \\
\hline Camk2b $b^{A 303 R} / A 303 R$ & $\begin{array}{l}\text { Mutant which cannot bind } \mathrm{Ca}^{2+} / \mathrm{CaM} \text { (mutation } \\
\text { prevents CaMKII } \beta \text { enzymatic activation, while } \\
\text { preserving its ability to bind to actin) }\end{array}$ & {$[34]$} \\
\hline Camk2b $b^{T 287 A} j^{T 287 A}$ & $\begin{array}{c}\text { Autophosphorylation-deficient mutant (mutation } \\
\text { blocks CaMKII } \beta \text { autonomous activity) }\end{array}$ & {$[33]$} \\
\hline Camk2b exon 13:TS/A knock-in mouse & $\begin{array}{l}\text { Mouse carrying phosphoblock mutations in the actin } \\
\text { binding domain (phosphorylation sites of this region } \\
\text { are critical for CaMKII detachment from F-actin) }\end{array}$ & [35] \\
\hline Camk $2 a^{-/-} ;$Camk2b $b^{-/-}$ & $\begin{array}{c}\text { Camk2a }^{-/-}[36] \text { and Camk2b } b^{-/}[20] \text { were used to } \\
\text { generate double mutants }\end{array}$ & [37] \\
\hline
\end{tabular}

\section{CaMKII $\beta$ in Neuronal Development}

Neuronal development is a sequential process from neuronal progenitor proliferation to synaptic integration. The failure of one of these developmental steps can heavily impact on subsequent brain formation and later function. Interestingly, gross histological examination of adult Camk $2 b^{-/-}$ mice revealed no significant differences in overall brain structure [20,32,34], implying that CaMKII $\beta$ might dispensable for normal brain development. However, further studies using overexpression or knockdown approaches in vitro or in vivo have suggested that CaMKII $\beta$ might have multiple functions in the late steps of this process, in particular during neuronal migration, dendrite morphogenesis, and spine/synapse formation. 


\subsection{CaMKII $\beta$ and Neuronal Migration}

After their birth, neurons migrate to reach defined locations, where they integrate into functional circuits. Recently, we and others have shown that CaMKII $\beta$ has a role during embryonic radial migration of cortical projections neurons [18,38]. Briefly, during the development of the cerebral cortex, projection neurons, born from progenitors in the germinal zone of the dorsal telencephalon, radially migrate following a route that is perpendicular to the ventricular surface before settling in their final laminar position [39]. Radial migration is a multi-step process that starts with the detachment of nascent neurons from the apical surface of the germinal ventricular zone (VZ) (Figure 2A step 1). Newly generated neurons then move to the intermediate zone (IZ), where they acquire a multipolar shape (Figure 2A step 2). Thereafter, neurons become bipolar, extending a leading process towards the pial surface and a trailing process in the opposite direction. Upon multi to bipolar transition, neurons establish dynamic contacts with radial glia fibers and subsequently use them as a scaffold for migrating to the upper part of the cortical plate (CP) using a mode of migration called locomotion (Figure 2A step 3).

A

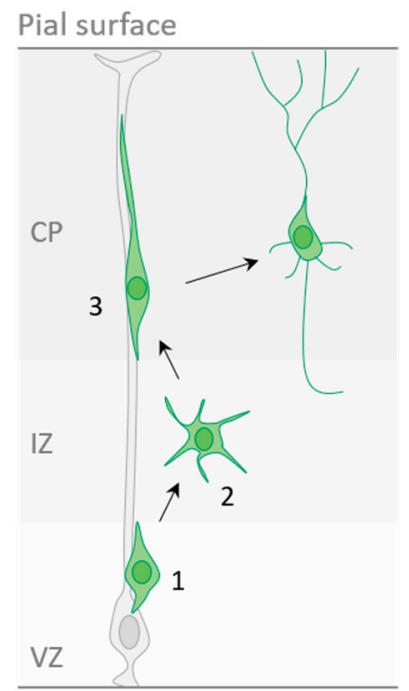

Ventricular surface
B

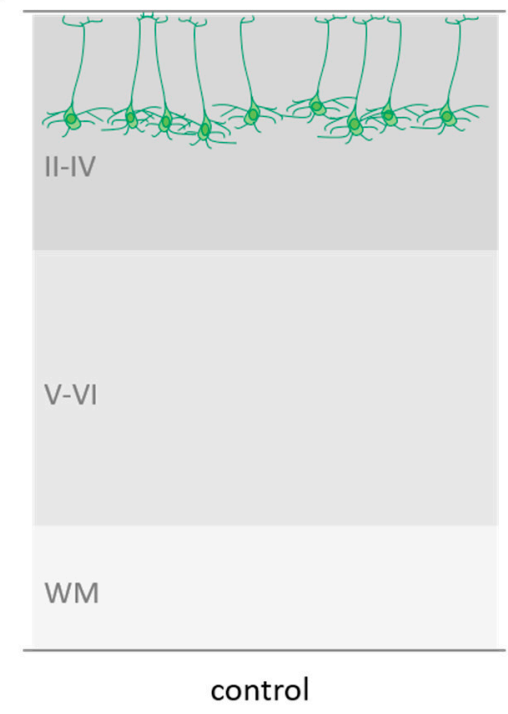

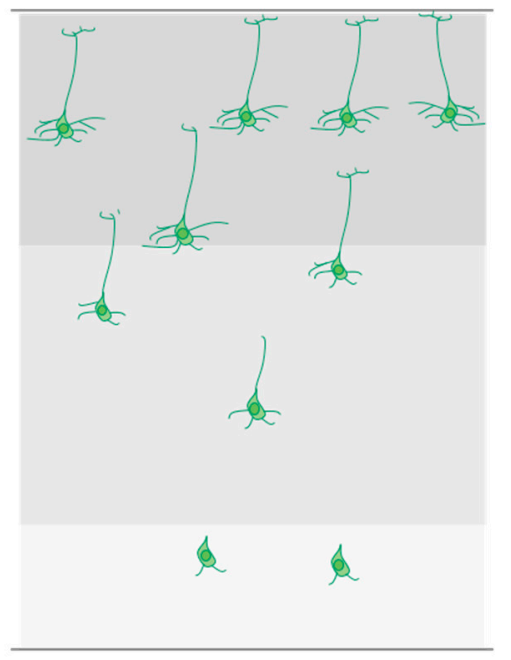

CaMKII $\beta$ overexpression

Figure 2. (A) Radial migration of projection neurons in the developing cerebral cortex. Step 1: newborn neurons detach from the ventricular surface. Step 2: nascent neurons migrate into the intermediate zone where they become transiently multipolar. Step 3: newborn neurons undergo a multipolar-bipolar transition and migrate along radial glia processes to finally detach and populate the cortical plate. VZ: ventricular zone; IZ: intermediate zone; CP: cortical plate. (B) Cortical neuron position in the early postnatal cortex in control condition of after CaMKII $\beta$ overexpression. II-IV: layers II to IV; V-VI: layer V and VI; WM: white matter.

Using knockdown or overexpression approaches via in utero electroporation, correct levels of CaMKII $\beta$ have been shown to be required for proper radial migration of projection neurons in two independent studies [18,38]. While CaMKII $\beta$ overexpression impairs this process in both studies, opposite results have been described after electroporation of the mouse cerebral cortex with CaMKII $\beta$ shRNAs. Indeed, after electroporation at E14.5 of a pool of five different CaMKII $\beta$ shRNAs (targeting CaMKII $\beta$, but not $\alpha$ ), Kury at al. observed migration defects at P0. While control electroporated neurons are located in the upper part of the $\mathrm{CP}$ at this stage, CaMKII $\beta$-silenced neurons are scattered throughout the entire cortical wall in this study [38]. Inversely, Nicole et al. found that the knockdown of CaMKII $\beta$ at E14.5, with one specific shRNA (targeting only CaMKII $\beta$, but not $\alpha, \gamma$, and $\delta$, and targeting the four splice variants of $\mathrm{CaMKII} \beta$ ), promotes the radial migration of cortical neurons. When CaMKII $\beta$ is silenced, neurons quickly leave the IZ after the multipolar-bipolar transition to reach the CP and then 
CaMKII $\beta$-deficient cells move faster in the CP. Consequently, at E17.5, more cells reach the upper part of the CP compared to control neurons [18]. This discrepancy between the results might be due to off-target effects, a lack of specificity of the shRNAs towards the CaMKII $\beta$ isoform, and/or to a variable action of these shRNA on the different splicing variants.

In the study of Nicole and colleagues, CaMKII $\beta$ overexpression at E14.5 significantly decreases the proportion of cells reaching the $\mathrm{CP}$ three days later, whereas the fraction in the IZ is concomitantly increased. At P14, a significant fraction of CaMKII $\beta$ overexpressing cells is still trapped in deep layers, indicating that this manipulation during embryogenesis has a long-term impact on neuronal positioning [18] (Figure 2B). In particular, CaMKII $\beta$ has been found to be essential for the multipolar-bipolar transition and for locomotion in the $\mathrm{CP}$, and these actions are primarily dependent on its actin-binding and oligomerization domains [18]. Indeed, the overexpression of CaMKII $\beta-\triangle F A B D$ or CaMKII $\beta-\triangle$ asso abolishes the capacity of CaMKII $\beta$ to impair the multipolar-bipolar conversion and to reduce the migration speed in the $\mathrm{CP}$ [18]. Moreover, electroporation of the phosphomimetic All D mutant (which is unable to bind to F-actin, see Table 1) also does not induce any migration defect, indicating that autophosphorylation sites within the FABD control CaMKII $\beta$ action in migrating neurons [18]. This action is also tightly linked to cofilin activity since F-actin-CaMKII $\beta$ interaction limits access of actin regulating proteins, like the actin-depolymerizing cofilin $[18,30]$. Interestingly, $\mathrm{Ca}^{2+}$ fluctuations have been described in migrating neurons $[40,41]$ and it has been proposed that CaMKII $\beta$ might constitute a link between $\mathrm{Ca}^{2+}$ signaling and the actin cytoskeleton in cortical migrating neurons. Thus $\mathrm{Ca}^{2+}$ increase in locomoting neurons might dissociate CaMKII $\beta$ from F-actin allowing for actin remodeling by actin-modifying proteins, such as cofilin, and thus the forward movement [18]. Finally, while the actin-binding and -bundling activities of CaMKII $\beta$ seem to be primarily involved in the regulation of cortical neuron migration, its kinase activity might also be implicated, since mutations that decrease or increase CaMKII $\beta$ auto-phosphorylation at Thr287 also affect migration in the developing cortex [38].

In contrast to the $\beta$ isoform, CaMKII $\alpha$ is not expressed in the embryonic cerebral cortex $[3,17,18]$, and reducing or increasing levels of wild-type CaMKII $\alpha$ does not affect cortical neuron migration [38]. Accordingly, CaMKII $\beta$ has a role in the radial migration of cortical projection neurons, but not CaMKII $\alpha$.

\subsection{CaMKIIß and Dendrite Formation/Pruning}

Once newborn neurons reach their final destination, they undergo dendrite morphogenesis with a first step of dendrite growth and arborization followed by a second step of dendrite retraction and pruning [42]. These steps are crucial for establishing accurate dendrite morphologies and, consequently, proper neural circuits in the brain.

The role of CaMKII $\beta$ in this process has been well described in granule neurons of the developing cerebellar cortex [15]. In vitro, the knockdown of CaMKII $\beta$ in these neurons induces more and longer dendrites, but has no effect on axon length, demonstrating that CaMKII $\beta$ specifically inhibits dendrite growth and arborization [15]. Similarly, in vivo, CaMKII $\beta$ silenced granule neurons exhibit longer dendrites with greater secondary and tertiary dendrite branching as compared to control neurons at P8, five days after the electroporation. At P12, while control neurons have a few short dendrites with simplified arbors compared to P8, CaMKII $\beta$-knockdown neurons show longer, more branched dendrite arbors with greater total dendrite length and dendrite number when compared to controls indicating that CaMKII $\beta$ silencing also impairs dendrite pruning [15]. Interestingly, CaMKII $\beta$ drives dendrite retraction and pruning from the centrosome. Puram et al. identified a unique centrosomal targeting sequence (CTS) within the variable region of CaMKII $\beta$ (but not CaMKII $\alpha$ ). This CTS mediates the specific interaction of CaMKII $\beta$ with the centrosomal targeting protein PCM1, which then induces the localization of CaMKII $\beta$ to the centrosome. There, CaMKII $\beta$ phosphorylates the E3 ubiquitin ligase Cdc20-APC (cell division cycle 20-anaphase promoting complex) at Ser51, which induces Cdc20 dispersion from the centrosome, thereby inhibiting centrosomal Cdc20-APC activity and triggering a switch from growth to retraction of dendrites [15]. In this study, the authors also demonstrate that 
CaMKII $\beta$ operates at the centrosome in a CaMKII $\alpha$-independent manner, thus unrevealing another isoform specific-function for CaMKII $\beta$. This function of CaMKII $\beta$ in the regulation of dendrite retraction has been also described in cultured hippocampal and cortical neurons [15] as well as, in vivo, in pyramidal cortical neurons and a similar mechanism seems to be involved in these cells [18]. Thus, CaMKII $\beta$ restricts the growth and arborization of dendrites in diverse populations of mammalian brain neurons. However, it should be noted that this function might be cell specific, since the complexity of dendritic branching is not significantly changed in Purkinje cells of Camk $2 b^{-/}$mutants as compared to the control mice [20].

\subsection{CaMKIIß and Spine/Synapse Formation}

While dendrites develop, they are progressively covered by small protrusions, called dendritic spines. These spines serve as the main sites of excitatory synapses in the brain. During the early stages of synaptogenesis, immature dendritic protrusions, which are classified as filopodia, rapidly protrude and retract from dendrites, allowing for neurons to find contact sites, which can then evolve into synapses. With development, filopodia are gradually replaced by mature mushroom-shaped spines [43]. Importantly, the actin filaments are a major structural element of the regulation of dendritic spine formation and morphology [44].

In young hippocampal cultured neurons, Fink et al. showed that CaMKII $\beta$ overexpression increases the fine architecture of the dendritic arbor in particular filopodia, whereas its knockdown has an opposite effect [28]. However, this ability of CaMKII $\beta$ to promote dendritic arborization decreases with age and its action becomes even opposite when neurons mature [28]. As neurons mature, CaMKII $\beta$ controls the motility of filopodia and synapse formation rather positively [28]. Again, only CaMKII $\beta$ has this activity, not CaMKII $\alpha$, most probably because it is dependent on CaMKII $\beta$ ability to interact with F-actin [28]. Besides its role during spinogenesis, CaMKII $\beta$ is also crucial for spine maintenance [9]. Indeed, CaMKII $\beta$ maintains mature spine structure through its F-actin binding and bundling activity, but not its kinase activity [9].

Similarly, in Purkinje cells, CaMKII $\beta$ promotes spine formation and elongation via its F-actin bundling activity [45]. In addition, protein kinase C (PKC)-mediated phosphorylation of CaMKII $\beta$ is responsible for the maintenance of the appropriate spine density and morphology in these cells. More precisely, PKC phosphorylates CaMKII $\beta$ at S315 under the control of group I metabotropic glutamate receptor (mGluR1) signaling, and this event results in dissociation of the CaMKII $\beta / F-a c t i n ~ c o m p l e x$, which then represses excessive spine formation and elongation in mature Purkinje cells [45].

While these data suggest that CaMKII $\beta$ is important for the control of spine density and morphology, other studies give somehow different conclusions. For example, Okamoto et al. observed that, after CaMKII $\beta$ knockdown in hippocampal organotypic slices, mature spines are converted to filopodia-like spines, but spine density is not modified [9]. Furthermore, in Camk $2 b^{-/-}$mice, Purkinje cells and hippocampal pyramidal cells from CA1 do not show any differences in spine density and/or morphology [20,34].

Although the initial observations in $\mathrm{Camk2b^{-/ }}$ mutants suggested that CaMKII $\beta$ is not required for normal neuronal development, the aforementioned studies inversely indicate that CaMKII $\beta$ seems to have several functions during this process. The strategy used to perturb CaMKII $\beta$ expression (knockdown, knockout, surexpression, in vitro/in vivo...) might explain the distinct conclusions. Indeed, germline mutations in Camk $2 b$ might result in homeostatic compensatory mechanisms that would prevent to see the changes that were observed in neurons shortly after an acute depletion in a limited population.

\section{CaMKII $\beta$ in Neuronal Plasticity}

One fundamental attribute of the brain is the plasticity of its synapses, namely a positive or negative change in efficacy of connections between neurons in response to neuronal activity. Depending on the specific pattern of stimulation and localization of neuron assemblies, individual synapses can increase 
or decrease the strength of their transmission, two processes called, respectively, long term potentiation (LTP) and long term depression (LTD). These changes in synapse functioning have been considered as a cellular model for the process of learning and memory (for review [46]). It is now well established that LTP induction results in $\mathrm{Ca}^{2+}$ entry, which activates CaMKII $\alpha$ localized close to the activated synapse. Subsequently, CaMKII $\alpha$ translocates to the synapse, where it binds to N-Methyl-D-aspartate (NMDA) receptors and produces the potentiation of the synaptic response by phosphorylating principal and auxiliary subunits of $\alpha$-amino-3-hydroxy-5-methyl-4-isoxazolepropionic acid (AMPA) receptors (for review [47]). This sequestration of CaMKII $\alpha$ to dendritic spines and the postsynaptic density (PSD) within a few seconds of stimulation is coupled to actin polymerization and the expansion of the stimulated spines [48], also called structural plasticity [49]. Blocking structural spine enlargement interferes with functional plasticity induction [30], which suggests that the functional and structural plasticity are tightly and mutually regulated. These structural and functional changes are short-lasting (1-4 h), unless stabilizing plasticity-related proteins (PRPs) are recruited. This recruitment depends on new protein synthesis and on a process of "synaptic tagging and capture", which explain how the newly synthesized proteins in the soma can selectively find the potentiated synapses (for review [50]). The postsynaptic capture of PRPs allows for the subsequent stabilization of spine structure, which enables maintenance of the functional change. This synaptic tagging process at the dendritic spine requires CaMKII activity and the newly formed F-actin complex that is both permissive and necessary for the remodeling of the PSD. Among the PRPs, Arc is rapidly upregulated by strong synaptic activity and it critically contributes to weakening adjacent synapses by promoting AMPA receptor endocytosis to prevent undesired enhanced activity in the vicinity of activated synapses. This process that is necessary for sustainably changing synaptic efficiency only on potentiated synapses is called "inverse synaptic tagging" [14].

In this whole complex cascade, CaMKII $\beta$ acts in concert with CaMKII $\alpha$, but with distinct functions to regulate both functional and structural plasticity and the synaptic tagging process, necessary for learning and memory.

\subsection{Molecular Mechanisms of CaMKIIß in Synaptic Plasticity}

The C-terminal association domain of CaMKII isoforms can form homo- or heteromeric assemblies of 12 to 14 mers, in which subunit composition seems to be dependent on isoform expressions (with unknown isoform preference). In the forebrain, the $\beta$ subunit of CaMKII constitutes approximately $30 \%$ of the total amount of CaMKII [19] and $80 \%$ in the cerebellum. As a consequence, the ratios of $\alpha$ and $\beta$ subunits are about 3:1 and 1:4 in adult forebrain and cerebellum, respectively [19]. In the holoenzyme, the presence of CaMKII $\beta$ plays a critical role in the subcellular localization and subsequent postsynaptic translocation of the entire CaMKII holozyme [8,29]. Indeed, in the basal condition, the CaMKII holoenzymes, via CaMKII $\beta$, are able to bind actin filaments, particularly in dendritic spines $[8,9,28,29,48]$. When CaMKII holoenzyme is activated by neuronal activity and the resultant $\mathrm{Ca}^{2+}$ influx, it detaches from F-actin and CaMKII holoenzymes can be recruited to the synapse to induce functional changes (Figure 1B). Thus, a small fraction of CaMKII $\beta$ is sufficient for docking the predominant CaMKII $\alpha$ to the actin cytoskeleton. In this configuration, CaMKII $\beta$ functions as a "targeting module" that localizes a higher number of CaMKII $\alpha$ to synaptic sites of action in order to facilitate functional plasticity [8].

In addition, the interaction of CaMKII $\beta$ with F-actin in basal state [9] limits the binding of other actin-binding molecules [30]. During neuronal plasticity, the CaMKII $\beta /$ actin interaction is abolished by $\mathrm{Ca}^{2+} / \mathrm{CaM}$ binding [8], which results in the detachment and release of unbundled F-actin. This opens a brief time window during which other actin binding partners have access to F-actin and can profoundly remodel the filaments $[51,52]$. The subsequent inactivation of CaMKII $\beta$ results in the re-bundling of the polymerized F-actin and re-stabilization of the new dendritic spine structure. Blocking the detachment of CaMKII $\beta$ from F-actin without affecting the kinase activity results in a deficit of both structural and 
functional plasticity [30], highlighting the crucial dual function of CaMKII $\beta$ as a negative regulator of actin remodeling in spines and as a molecular-temporal gate of synaptic plasticity.

More recently, a potential role of a dynamic interaction between inactive CaMKII $\beta$ and Arc has been shown. This interaction would allow Arc to be preferentially maintained at inactive synapses rather than active synapses. CaMKII-stabilized Arc may efficiently contribute to promoting AMPA receptor clearance from the inactive synapses. In this "inverse synaptic tagging process", CaMKII $\beta$ acts as a scaffold for Arc in dendritic spines [14]. In addition, it has been recently suggested that local CaMKII $\alpha$ translation at activated synapses $[53,54]$ and subunit exchange inside the CaMKII holoenzyme that is triggered by CaMKII activation $[55,56]$ would aid local replacement of the $\beta$ isoform in CaMKII holoenzyme, releasing CaMKII $\beta$ to the neighboring non-potentiated synapses [5].

\subsection{Role of CaMKIIß in LTP (Hippocampal and Cerebellar)}

In contrast to numerous studies on CaMKII $\alpha$, the analysis of the role that is played by CaMKII $\beta$ in LTP has been carried on in limited experiments. By selectively increasing CaMKII $\beta$ expression in the dentate gyrus (DG), the group of J. Tsien has demonstrated that elevated CaMKII $\beta$ activity leads to reduced LTP in the perforant path of the DG [57]. However, the inducible chemical genetic method used also increases the $\beta / \alpha$ ratio and changes the composition of the CaMKII holoenzyme. Because CaMKII $\beta$ has an F-actin binding module, which confers the anchoring of the CaMKII complex at the base of the synaptic spine, the numerical increase of CaMKII $\beta$ in CaMKII holoenzyme might alter the biophysical properties of the holoenzyme (i.e., the CaMKII holoenzyme might be slower to translocate from the base of dendritic spines to PSD or to fall off faster from PSD). In contrast, by using the Camk $2 b^{-/}$mutant, Borgesius et al. (2011) clearly established that Schaffer collateral-CA1 LTP is highly dependent upon the presence of CaMKII $\beta$. But interestingly LTP was unaffected in Camk $2 b^{A 303 R}$ mutant, in which the Ca2+/CaM-dependent activation of CaMKII $\beta$ is prevented, while the F-actin binding and bundling property are preserved. This study pinpoints that CaMKII $\beta$ can modulate LTP via a non-enzymatic role, as a targeting module of CaMKII $\alpha$. More recently, the relative importance of CaMKII $\alpha$ and CaMKII $\beta$ in LTP has been analyzed while using a CRISPR-based system to delete both CaMKII $\alpha$ and $\beta$ (DKO) and using rescue experiments to restore the defects that are caused by the DKO by expressing back CaMKII subunits [58]. First, these authors confirmed that the deletion of CaMKII $\beta$ blocks LTP, similar to the deletion of CaMKII $\alpha$. However, interestingly, while CaMKII $\alpha$ fully rescued LTP in the DKO, CaMKII $\beta$ was unable to rescue LTP, either in the DKO or after CaMKII $\alpha$ deletion alone, indicating that CaMKII $\beta$ is not required for the full expression of LTP.

Since CaMKII $\beta$ is highly expressed in the cerebellum, its role has also been studied in cerebellar synaptic plasticity. The plasticity rules are different in the cerebellum when compared to the hippocampus. The stimulation of parallel fibers in combination with climbing fibers results in a high influx of $\mathrm{Ca}^{2+}$ and the recruitment of CaMKII $\alpha$, resulting in LTD at the parallel fiber-Purkinje cell synapses [59]. Interestingly, in Camk2 $b^{-/}$mutant mice ${ }^{-}$, the loss of CaMKII $\beta$ results in a complete reversal of the plasticity rules [20]. A protocol that induced synaptic depression in wild type mice resulted in synaptic potentiation in Camk $2 b$ knock-out-mice and vice-versa. Although the precise mechanism is unclear, a mathematical model that was recently developed suggests that the balance of CaMKII-mediated phosphorylation and protein phosphatase 2B (PP2B)-mediated dephosphorylation of AMPA receptors can determine whether LTD or LTP occurs in cerebellar purkinje cells. This computational model replicates observations that CaMKII $\beta$ controls the direction of plasticity. It also demonstrates that the binding of F-actin to CaMKII can enable the $\beta$ isoform of the kinase to regulate bidirectional plasticity at these synapses [60].

\subsection{CaMKII $\beta$ and Memory}

Based on the role of CaMKII $\beta$ in LTP, studies have been also conducted in order to understand the specific role of CaMKII $\beta$ in learning and memory processes. Increased activity of CaMKII $\beta$ selectively in the DG, using the inducible chemical genetic model, induces a reversal learning deficits in the 
radial arm maze task and the water cross maze [61], but a normal memory formation, one day after training in novel object recognition, and contextual fear memory. However, their contextual fear memory is severely impaired at longer retention delays (10 days) [57], which suggests that the $\beta$ isoform could have an effect in long term memory consolidation. On the other hand, Camk $2 b^{-/-}$mutant mice show impairment in novel object recognition when tested $4 \mathrm{~h}$ after training [32] and in fear conditioning memory when tested $24 \mathrm{~h}$ after training [34]. Interestingly, in this last work, the authors found that CaMKII $\alpha$ expression levels are not altered in the Camk $2 b^{-/-}$mice but its location to synapses is decreased by almost $40 \%$. This prompted the authors to study whether the observed memory deficits were a side-effect of decreased CaMKII $\alpha$ localization in PSD. To test this, they used the Camk $2 b^{A 303 R}$ mouse model and showed that fear conditioning performance was normal, in contrast to what they observed in Camk $2 b^{-/}$mice. CaMKII $\alpha$ abnormal distribution observed in Camk2b $b^{-/}$was not seen in Camk $2 b^{A 303 R}$ mice. This last result led to the important conclusion that CaMKII $\beta$ binding to F-actin is necessary for CaMKII $\alpha$ translocation to spines, but not its catalytic activity, and consequently for memory processes. The discrepancy between observations that are based on knock-in mouse lines versus overexpression of mutant subunits might be also due to the relative stoichiometry of CaMKII $\beta$ and CaMKII $\alpha$, which might influence CaMKII $\alpha$ interactions in the PSD. Indeed, Silva et colleagues have reported that, whereas the heterozygous Camk $2 a^{-} /^{+}$(with a probably higher $\beta / \alpha$ ratio) exhibit normal learning and memory after 1-3 days of retention, these mice show a severe impairment of retention of long term memory at 10-50 days [62], as observed with the chemical genetic method that increase CaMKII $\beta$ (with a probably higher $\beta / \alpha$ ratio) [57] Thus, a higher content of CaMKII $\beta$ within the holoenzymes might cause the CaMKII complex to be slower to translocate to the PSD. At the opposite, the lack of CaMKII $\beta$ could reduce the synaptic location of CaMKII $\alpha$ and also alter the bioavailability closed to the PSD. Altogether, these results strongly suggest an essential, but non-enzymatic role for CaMKII $\beta$ in learning and memory, most probably by properly targeting the CAMKII complex.

\section{CaMKII $\beta$ and Brain Disorders}

As a consequence of its important physiological roles in neuronal development and plasticity, alterations in CaMKII $\beta$ expression/function could contribute to the pathogenesis of many brain disorders. In this vein, a series of recent studies suggest that CaMKII $\beta$ dysfunction in the brain may underlie multiple neuropsychiatric and neurodevelopmental disorders.

In 2017, Kury et al. identified, via a whole-exome sequencing approach, seven rare de novo $C A M K 2 B$ variants in 10 unrelated individuals with mild to severe intellectual disability [38]. These individuals also show language impairment and behavioral anomalies, such as abnormal emotion/affect behavior or seizures for some of them. Interestingly, most of the described mutations decrease or increase CaMKII $\beta$ auto-phosphorylation at Thr287 and the expression of the corresponding mutant forms of CaMKII $\beta$ in the mouse developing cerebral cortex affect neuronal migration [38]. Few months later, another collaborative study published two other de novo variants in $C A M K 2 B$ that impair the autoinhibition of CaMKII. These mutations were identified in two individuals amongst a population of 976 individuals with intellectual disability, developmental delay, and epilepsy [63].

Several converging evidence also support a potential role of CaMKII $\beta$ in the pathophysiology of schizophrenia. Indeed, the prefrontal cortex (a key brain region that is involved in the cognitive symptoms of the disease) of patients who had schizophrenia shows elevated levels of CaMKII $\beta$ transcripts [64,65]. Moreover, an increase of CaMKII $\beta$ mRNA was found in several animal models of schizophrenia, such as postnatal maternal deprivation and pubertal stress [66], as well as amphetamine sensitization [67].

In addition to neurodevelopmental disorders, CaMKII $\beta$ might be a molecular determinant of depression. Indeed, its expression is increased at the mRNA level in the human frontal cortex of depression tissues [65] and, at the protein level, CaMKII $\beta$ is significantly upregulated in the lateral habenula (nucleus that has emerged as a key brain region in aversive behaviors and the pathophysiology of depression) of animal models of depression and down-regulated by antidepressants [68]. Similarly, 
in the hippocampal CA1, CaMKII $\beta$ is significantly upregulated in depressed rats, while antidepressant treatment downregulated this protein [69]. Furthermore, increasing CaMKII $\beta$ in the lateral habenula through a viral approach is sufficient for producing profound depressive symptoms, including anhedonia and behavioral despair, in both rats and mice [68]. To note, the overexpression of CaMKII $\alpha$ at a similar infection rate does not cause similar depressive-like effects. Conversely, down-regulation of CaMKII $\beta$ levels in this structure, blocking its activity or its target molecule the glutamate receptor GluR1 reverse the depressive symptoms [68]. A similar manipulation of CaMKII $\beta$ (overexpression and downregulation) in the CA1 gives similar results on depressive-like behavior [69]. CaMKII $\beta$ seems to act upstream of the cyclo-oxygenase (COX)-2/prostaglandin E2 (PGE2) neuroinflammatory signaling pathway in this hippocampal region [69].

\section{Conclusions}

The recent findings on CaMKII $\beta$ has demonstrated that this isoform has major biological functions in the brain, and it might be a potential target for therapeutic interventions in diverse brain disorders. However, further studies are required to better define the spatiotemporal and subcellular functions of CaMKII $\beta$, but also to provide mechanistic insights into CaMKII $\beta$ action. A better understanding of the role(s) played by the individual CaMKII $\beta$ splice variants represents another important challenge. Finally, it would now be interesting to consider CaMKII $\gamma$ and $\delta$, which are able to bind to F-actin [70], but have been also understated.

Author Contributions: E.P. wrote parts 1, 2, 4, 5 and O.N. wrote part 3. All authors have read and agreed to the published version of the manuscript.

Funding: This work was supported by INSERM, CNRS, University of Bordeaux and ANR (ANR-19-CE16-0014-01 and ANR-14-CE13-0017-01).

Conflicts of Interest: The authors declare no conflict of interest. The funders had no role in the writing of the manuscript.

\section{Abbreviations}

$\begin{array}{ll}\text { AMPA } & \alpha \text {-amino-3-hydroxy-5-methyl-4-isoxazolepropionic acid } \\ \mathrm{Ca}^{2+} / \mathrm{CaM} & \mathrm{Ca}^{2+} \text {-bound calmodulin } \\ \text { CaMKII } & \text { calcium/calmodulin-dependent protein kinase II } \\ \text { Cdc20-APC } & \text { cell division cycle 20-anaphase promoting complex } \\ \text { COX-2 } & \text { cyclo-oxygenase-2 } \\ \text { CP } & \text { cortical plate } \\ \text { CTS } & \text { centrosomal targeting sequence } \\ \text { DG } & \text { dentate gyrus } \\ \text { DKO } & \text { deletion of both CaMKII } \alpha \text { and CaMKII } \beta \\ \text { FABD } & \text { F-actin binding domain } \\ \text { F-actin } & \text { filamentous-actin } \\ \text { IZ } & \text { intermediate zone } \\ \text { LTD } & \text { long-term depression } \\ \text { LTP } & \text { long-term potentiation } \\ \text { mGluR1 } & \text { group I metabotropic glutamate receptor } \\ \text { NMDA } & \text { N-Methyl-D-aspartate } \\ \text { PCM1 } & \text { pericentriolar material 1 } \\ \text { PGE2 } & \text { prostaglandin E2 } \\ \text { PKC } & \text { protein kinase C } \\ \text { PP2B } & \text { protein phosphatase 2B } \\ \text { PRP } & \text { plasticity-related proteins } \\ \text { PSD } & \text { post-synaptic density } \\ \text { VZ } & \text { ventricular zone } \\ \text { WM } & \text { white matter }\end{array}$




\section{References}

1. Erondu, N.E.; Kennedy, M.B. Regional distribution of type II Ca2+/calmodulin-dependent protein kinase in rat brain. J. Neurosci. Off. J. Soc. Neurosci. 1985, 5, 3270-3277. [CrossRef]

2. Tombes, R.M.; Faison, M.O.; Turbeville, J.M. Organization and evolution of multifunctional $\mathrm{Ca}(2+) / \mathrm{CaM}-d e p e n d e n t$ protein kinase genes. Gene 2003, 322, 17-31. [CrossRef] [PubMed]

3. Bayer, K.U.; Lohler, J.; Schulman, H.; Harbers, K. Developmental expression of the CaM kinase II isoforms: Ubiquitous gamma- and delta-CaM kinase II are the early isoforms and most abundant in the developing nervous system. Brain Res. Mol. Brain Res. 1999, 70, 147-154. [CrossRef]

4. Brocke, L.; Chiang, L.W.; Wagner, P.D.; Schulman, H. Functional implications of the subunit composition of neuronal CaM kinase II. J. Biol. Chem. 1999, 274, 22713-22722. [CrossRef] [PubMed]

5. Bayer, K.U.; Schulman, H. CaM Kinase: Still Inspiring at 40. Neuron 2019, 103, 380-394. [CrossRef]

6. Hell, J.W. CaMKII: Claiming center stage in postsynaptic function and organization. Neuron 2014, 81, $249-265$. [CrossRef]

7. Tobimatsu, T.; Fujisawa, H. Tissue-specific expression of four types of rat calmodulin-dependent protein kinase II mRNAs. J. Biol. Chem. 1989, 264, 17907-17912.

8. Shen, K.; Teruel, M.N.; Subramanian, K.; Meyer, T. CaMKIIbeta functions as an F-actin targeting module that localizes CaMKIIalpha/beta heterooligomers to dendritic spines. Neuron 1998, 21, 593-606. [CrossRef]

9. Okamoto, K.; Narayanan, R.; Lee, S.H.; Murata, K.; Hayashi, Y. The role of CaMKII as an F-actin-bundling protein crucial for maintenance of dendritic spine structure. Proc. Natl. Acad. Sci. USA 2007, 104, 6418-6423. [CrossRef]

10. Brocke, L.; Srinivasan, M.; Schulman, H. Developmental and regional expression of multifunctional $\mathrm{Ca}+/$ calmodulin-dependent protein kinase isoforms in rat brain. J. Neurosci. Off. J. Soc. Neurosci. 1995, 15, 6797-6808. [CrossRef]

11. Cook, S.G.; Bourke, A.M.; O’Leary, H.; Zaegel, V.; Lasda, E.; Mize-Berge, J.; Quillinan, N.; Tucker, C.L.; Coultrap, S.J.; Herson, P.S.; et al. Analysis of the CaMKIIalpha and beta splice-variant distribution among brain regions reveals isoform-specific differences in holoenzyme formation. Sci. Rep. 2018, 8, 5448. [CrossRef] [PubMed]

12. O'Leary, H.; Lasda, E.; Bayer, K.U. CaMKIIbeta association with the actin cytoskeleton is regulated by alternative splicing. Mol. Biol. Cell 2006, 17, 4656-4665. [CrossRef] [PubMed]

13. Zheng, J.; Redmond, L.; Xu, C.; Kuang, J.; Liao, W. Alternative splicing in the variable domain of CaMKIIbeta affects the level of F-actin association in developing neurons. Int. J. Clin. Exp. Pathol. 2014, 7, 2963-2975.

14. Okuno, H.; Akashi, K.; Ishii, Y.; Yagishita-Kyo, N.; Suzuki, K.; Nonaka, M.; Kawashima, T.; Fujii, H.; Takemoto-Kimura, S.; Abe, M.; et al. Inverse synaptic tagging of inactive synapses via dynamic interaction of Arc/Arg3.1 with CaMKIIbeta. Cell 2012, 149, 886-898. [CrossRef]

15. Puram, S.V.; Kim, A.H.; Ikeuchi, Y.; Wilson-Grady, J.T.; Merdes, A.; Gygi, S.P.; Bonni, A. A CaMKIIbeta signaling pathway at the centrosome regulates dendrite patterning in the brain. Nat. Neurosci. 2011, 14, 973-983. [CrossRef]

16. Gaertner, T.R.; Kolodziej, S.J.; Wang, D.; Kobayashi, R.; Koomen, J.M.; Stoops, J.K.; Waxham, M.N. Comparative analyses of the three-dimensional structures and enzymatic properties of alpha, beta, gamma and delta isoforms of Ca2+-calmodulin-dependent protein kinase II. J. Biol. Chem. 2004, 279, 12484-12494. [CrossRef] [PubMed]

17. Lin, Y.C.; Redmond, L. CaMKIIbeta binding to stable F-actin in vivo regulates F-actin filament stability. Proc. Natl. Acad. Sci. USA 2008, 105, 15791-15796. [CrossRef] [PubMed]

18. Nicole, O.; Bell, D.M.; Leste-Lasserre, T.; Doat, H.; Guillemot, F.; Pacary, E. A novel role for CAMKIIbeta in the regulation of cortical neuron migration: Implications for neurodevelopmental disorders. Mol. Psychiatry 2018, 23, 2209-2226. [CrossRef]

19. Miller, S.G.; Kennedy, M.B. Distinct forebrain and cerebellar isozymes of type II Ca2+/calmodulin-dependent protein kinase associate differently with the postsynaptic density fraction. J. Biol. Chem. 1985, 260, 9039-9046.

20. Van Woerden, G.M.; Hoebeek, F.E.; Gao, Z.; Nagaraja, R.Y.; Hoogenraad, C.C.; Kushner, S.A.; Hansel, C.; De Zeeuw, C.I.; Elgersma, Y. betaCaMKII controls the direction of plasticity at parallel fiber-Purkinje cell synapses. Nat. Neurosci. 2009, 12, 823-825. [CrossRef] 
21. Liu, X.B.; Jones, E.G. Localization of alpha type II calcium calmodulin-dependent protein kinase at glutamatergic but not gamma-aminobutyric acid (GABAergic) synapses in thalamus and cerebral cortex. Proc. Natl. Acad. Sci. USA 1996, 93, 7332-7336. [CrossRef] [PubMed]

22. Sik, A.; Hajos, N.; Gulacsi, A.; Mody, I.; Freund, T.F. The absence of a major Ca2+ signaling pathway in GABAergic neurons of the hippocampus. Proc. Natl. Acad. Sci. USA 1998, 95, 3245-3250. [CrossRef] [PubMed]

23. Thiagarajan, T.C.; Piedras-Renteria, E.S.; Tsien, R.W. alpha- and betaCaMKII. Inverse regulation by neuronal activity and opposing effects on synaptic strength. Neuron 2002, 36, 1103-1114. [CrossRef]

24. Conlee, J.W.; Shapiro, S.M.; Churn, S.B. Expression of the alpha and beta subunits of Ca2+/calmodulin kinase II in the cerebellum of jaundiced Gunn rats during development: A quantitative light microscopic analysis. Acta Neuropathol. 2000, 99, 393-401. [CrossRef] [PubMed]

25. Cahoy, J.D.; Emery, B.; Kaushal, A.; Foo, L.C.; Zamanian, J.L.; Christopherson, K.S.; Xing, Y.; Lubischer, J.L.; Krieg, P.A.; Krupenko, S.A.; et al. A transcriptome database for astrocytes, neurons, and oligodendrocytes: A new resource for understanding brain development and function. J. Neurosci. Off. J. Soc. Neurosci. 2008, 28, 264-278. [CrossRef] [PubMed]

26. Waggener, C.T.; Dupree, J.L.; Elgersma, Y.; Fuss, B. CaMKIIbeta regulates oligodendrocyte maturation and CNS myelination. J. Neurosci. Off. J. Soc. Neurosci. 2013, 33, 10453-10458. [CrossRef]

27. Bennett, M.K.; Erondu, N.E.; Kennedy, M.B. Purification and characterization of a calmodulin-dependent protein kinase that is highly concentrated in brain. J. Biol. Chem. 1983, 258, 12735-12744.

28. Fink, C.C.; Bayer, K.U.; Myers, J.W.; Ferrell, J.E., Jr.; Schulman, H.; Meyer, T. Selective regulation of neurite extension and synapse formation by the beta but not the alpha isoform of CaMKII. Neuron 2003, 39, $283-297$. [CrossRef]

29. Shen, K.; Meyer, T. Dynamic control of CaMKII translocation and localization in hippocampal neurons by NMDA receptor stimulation. Science 1999, 284, 162-166. [CrossRef]

30. Kim, K.; Lakhanpal, G.; Lu, H.E.; Khan, M.; Suzuki, A.; Hayashi, M.K.; Narayanan, R.; Luyben, T.T.; Matsuda, T.; Nagai, T.; et al. A Temporary Gating of Actin Remodeling during Synaptic Plasticity Consists of the Interplay between the Kinase and Structural Functions of CaMKII. Neuron 2015, 87, 813-826. [CrossRef]

31. Gao, Z.; van Woerden, G.M.; Elgersma, Y.; De Zeeuw, C.I.; Hoebeek, F.E. Distinct roles of alpha- and betaCaMKII in controlling long-term potentiation of GABAA-receptor mediated transmission in murine Purkinje cells. Front. Cell. Neurosci. 2014, 8, 16. [CrossRef] [PubMed]

32. Bachstetter, A.D.; Webster, S.J.; Tu, T.; Goulding, D.S.; Haiech, J.; Watterson, D.M.; Van Eldik, L.J. Generation and behavior characterization of CaMKIIbeta knockout mice. PLoS ONE 2014, 9, e105191. [CrossRef] [PubMed]

33. Kool, M.J.; van de Bree, J.E.; Bodde, H.E.; Elgersma, Y.; van Woerden, G.M. The molecular, temporal and region-specific requirements of the beta isoform of Calcium/Calmodulin-dependent protein kinase type 2 (CAMK2B) in mouse locomotion. Sci. Rep. 2016, 6, 26989. [CrossRef] [PubMed]

34. Borgesius, N.Z.; van Woerden, G.M.; Buitendijk, G.H.; Keijzer, N.; Jaarsma, D.; Hoogenraad, C.C.; Elgersma, Y. betaCaMKII plays a nonenzymatic role in hippocampal synaptic plasticity and learning by targeting alphaCaMKII to synapses. J. Neurosci. Off. J. Soc. Neurosci. 2011, 31, 10141-10148. [CrossRef]

35. Kim, K.; Suzuki, A.; Kojima, H.; Kawamura, M.; Miya, K.; Abe, M.; Yamada, I.; Furuse, T.; Wakana, S.; Sakimura, K.; et al. Autophosphorylation of F-actin binding domain of CaMKIlbeta is required for fear learning. Neurobiol. Learn. Mem. 2019, 157, 86-95. [CrossRef]

36. Elgersma, Y.; Fedorov, N.B.; Ikonen, S.; Choi, E.S.; Elgersma, M.; Carvalho, O.M.; Giese, K.P.; Silva, A.J. Inhibitory autophosphorylation of CaMKII controls PSD association, plasticity, and learning. Neuron 2002, 36, 493-505. [CrossRef]

37. Kool, M.J.; Proietti Onori, M.; Borgesius, N.Z.; van de Bree, J.E.; Elgersma-Hooisma, M.; Nio, E.; Bezstarosti, K.; Buitendijk, G.H.S.; Aghadavoud Jolfaei, M.; Demmers, J.A.A.; et al. CAMK2-Dependent Signaling in Neurons Is Essential for Survival. J. Neurosci. Off. J. Soc. Neurosci. 2019, 39, 5424-5439. [CrossRef]

38. Kury, S.; van Woerden, G.M.; Besnard, T.; Proietti Onori, M.; Latypova, X.; Towne, M.C.; Cho, M.T.; Prescott, T.E.; Ploeg, M.A.; Sanders, S.; et al. De Novo Mutations in Protein Kinase Genes CAMK2A and CAMK2B Cause Intellectual Disability. Am. J. Hum. Genet. 2017, 101, 768-788. [CrossRef]

39. Azzarelli, R.; Guillemot, F.; Pacary, E. Function and regulation of Rnd proteins in cortical projection neuron migration. Front. Neurosci. 2015, 9, 19. [CrossRef] 
40. Komuro, H.; Rakic, P. Intracellular Ca2+ fluctuations modulate the rate of neuronal migration. Neuron 1996, 17, 275-285. [CrossRef]

41. Rash, B.G.; Ackman, J.B.; Rakic, P. Bidirectional radial $\mathrm{Ca}(2+)$ activity regulates neurogenesis and migration during early cortical column formation. Sci. Adv. 2016, 2, e1501733. [CrossRef] [PubMed]

42. Puram, S.V.; Bonni, A. Cell-intrinsic drivers of dendrite morphogenesis. Development 2013, 140, 4657-4671. [CrossRef] [PubMed]

43. Hering, H.; Sheng, M. Dendritic spines: Structure, dynamics and regulation. Nat. Rev. Neurosci. 2001, 2, 880-888. [CrossRef] [PubMed]

44. Hlushchenko, I.; Koskinen, M.; Hotulainen, P. Dendritic spine actin dynamics in neuronal maturation and synaptic plasticity. Cytoskeleton 2016, 73, 435-441. [CrossRef] [PubMed]

45. Sugawara, T.; Hisatsune, C.; Miyamoto, H.; Ogawa, N.; Mikoshiba, K. Regulation of spinogenesis in mature Purkinje cells via mGluR/PKC-mediated phosphorylation of CaMKIIbeta. Proc. Natl. Acad. Sci. USA 2017, 114, E5256-E5265. [CrossRef]

46. Sweatt, J.D. Neural plasticity and behavior—sixty years of conceptual advances. J. Neurochem. 2016, 139 Suppl. 2, 179-199. [CrossRef]

47. Lisman, J.; Yasuda, R.; Raghavachari, S. Mechanisms of CaMKII action in long-term potentiation. Nat. Rev.. Neurosci. 2012, 13, 169-182. [CrossRef]

48. Okamoto, K.; Nagai, T.; Miyawaki, A.; Hayashi, Y. Rapid and persistent modulation of actin dynamics regulates postsynaptic reorganization underlying bidirectional plasticity. Nat. Neurosci. 2004, 7, 1104-1112. [CrossRef]

49. Bosch, M.; Hayashi, Y. Structural plasticity of dendritic spines. Curr. Opin. Neurobiol. 2012, 22, 383-388. [CrossRef]

50. Redondo, R.L.; Morris, R.G. Making memories last: The synaptic tagging and capture hypothesis. Nat. Rev.. Neurosci. 2011, 12, 17-30. [CrossRef]

51. Bosch, M.; Castro, J.; Saneyoshi, T.; Matsuno, H.; Sur, M.; Hayashi, Y. Structural and molecular remodeling of dendritic spine substructures during long-term potentiation. Neuron 2014, 82, 444-459. [CrossRef] [PubMed]

52. Okamoto, K.; Bosch, M.; Hayashi, Y. The roles of CaMKII and F-actin in the structural plasticity of dendritic spines: A potential molecular identity of a synaptic tag? Physiology 2009, 24, 357-366. [CrossRef] [PubMed]

53. Burgin, K.E.; Waxham, M.N.; Rickling, S.; Westgate, S.A.; Mobley, W.C.; Kelly, P.T. In situ hybridization histochemistry of Ca2+/calmodulin-dependent protein kinase in developing rat brain. J. Neurosci. Off. J. Soc. Neurosci. 1990, 10, 1788-1798. [CrossRef]

54. Mayford, M.; Bach, M.E.; Huang, Y.Y.; Wang, L.; Hawkins, R.D.; Kandel, E.R. Control of memory formation through regulated expression of a CaMKII transgene. Science 1996, 274, 1678-1683. [CrossRef]

55. Bhattacharyya, M.; Stratton, M.M.; Going, C.C.; McSpadden, E.D.; Huang, Y.; Susa, A.C.; Elleman, A.; Cao, Y.M.; Pappireddi, N.; Burkhardt, P.; et al. Molecular mechanism of activation-triggered subunit exchange in $\mathrm{Ca}(2+)$ /calmodulin-dependent protein kinase II. eLife 2016, 5, e13405. [CrossRef]

56. Stratton, M.; Lee, I.H.; Bhattacharyya, M.; Christensen, S.M.; Chao, L.H.; Schulman, H.; Groves, J.T.; Kuriyan, J. Activation-triggered subunit exchange between CaMKII holoenzymes facilitates the spread of kinase activity. eLife 2014, 3, e01610. [CrossRef]

57. Cho, M.H.; Cao, X.; Wang, D.; Tsien, J.Z. Dentate gyrus-specific manipulation of beta-Ca2+/calmodulin-dependent kinase II disrupts memory consolidation. Proc. Natl. Acad. Sci. USA 2007, 104, 16317-16322. [CrossRef]

58. Incontro, S.; Diaz-Alonso, J.; Iafrati, J.; Vieira, M.; Asensio, C.S.; Sohal, V.S.; Roche, K.W.; Bender, K.J.; Nicoll, R.A. The CaMKII/NMDA receptor complex controls hippocampal synaptic transmission by kinase-dependent and independent mechanisms. Nat. Commun. 2018, 9, 2069. [CrossRef]

59. Hansel, C.; de Jeu, M.; Belmeguenai, A.; Houtman, S.H.; Buitendijk, G.H.; Andreev, D.; De Zeeuw, C.I.; Elgersma, Y. alphaCaMKII Is essential for cerebellar LTD and motor learning. Neuron 2006, 51, 835-843. [CrossRef]

60. Pinto, T.M.; Schilstra, M.J.; Roque, A.C.; Steuber, V. Binding of Filamentous Actin to CaMKII as Potential Regulation Mechanism of Bidirectional Synaptic Plasticity by beta CaMKII in Cerebellar Purkinje Cells. Sci. Rep. 2020, 10, 9019. [CrossRef] 
61. Yin, P.; Xu, H.; Wang, Q.; Wang, J.; Yin, L.; Xu, M.; Xie, Z.; Liu, W.; Cao, X. Overexpression of betaCaMKII impairs behavioral flexibility and NMDAR-dependent long-term depression in the dentate gyrus. Neuropharmacology 2017, 116, 270-287. [CrossRef] [PubMed]

62. Frankland, P.W.; Bontempi, B.; Talton, L.E.; Kaczmarek, L.; Silva, A.J. The involvement of the anterior cingulate cortex in remote contextual fear memory. Science 2004, 304, 881-883. [CrossRef] [PubMed]

63. Akita, T.; Aoto, K.; Kato, M.; Shiina, M.; Mutoh, H.; Nakashima, M.; Kuki, I.; Okazaki, S.; Magara, S.; Shiihara, T.; et al. De novo variants in CAMK2A and CAMK2B cause neurodevelopmental disorders. Ann. Clin. Transl. Neurol. 2018, 5, 280-296. [CrossRef] [PubMed]

64. Novak, G.; Seeman, P.; Tallerico, T. Schizophrenia: Elevated mRNA for calcium-calmodulin-dependent protein kinase IIbeta in frontal cortex. Brain Res. Mol. Brain Res. 2000, 82, 95-100. [CrossRef]

65. Novak, G.; Seeman, P.; Tallerico, T. Increased expression of calcium/calmodulin-dependent protein kinase IIbeta in frontal cortex in schizophrenia and depression. Synapse 2006, 59, 61-68. [CrossRef]

66. Novak, G.; Fan, T.; O’Dowd, B.F.; George, S.R. Postnatal maternal deprivation and pubertal stress have additive effects on dopamine D2 receptor and CaMKII beta expression in the striatum. Int. J. Dev. Neurosci. Off. J. Int. Soc. Dev. Neurosci. 2013, 31, 189-195. [CrossRef]

67. Greenstein, R.; Novak, G.; Seeman, P. Amphetamine sensitization elevates CaMKIIbeta mRNA. Synapse 2007, 61, 827-834. [CrossRef]

68. Li, K.; Zhou, T.; Liao, L.; Yang, Z.; Wong, C.; Henn, F.; Malinow, R.; Yates, J.R., Jr.; Hu, H. betaCaMKII in lateral habenula mediates core symptoms of depression. Science 2013, 341, 1016-1020. [CrossRef]

69. Song, Q.; Fan, C.; Wang, P.; Li, Y.; Yang, M.; Yu, S.Y. Hippocampal CA1 betaCaMKII mediates neuroinflammatory responses via COX-2/PGE2 signaling pathways in depression. J. Neuroinflammation 2018, 15, 338. [CrossRef]

70. Hoffman, L.; Farley, M.M.; Waxham, M.N. Calcium-calmodulin-dependent protein kinase II isoforms differentially impact the dynamics and structure of the actin cytoskeleton. Biochemistry 2013, 52, 1198-1207. [CrossRef]

(C) 2020 by the authors. Licensee MDPI, Basel, Switzerland. This article is an open access article distributed under the terms and conditions of the Creative Commons Attribution (CC BY) license (http://creativecommons.org/licenses/by/4.0/). 